\title{
Treinamento e desenvolvimento como instrumento de retenção de talentos nas organizações
}

Este trabalho trata da importância do subsistema treinamento e desenvolvimento como uma fonte de capacitação, aprimoramento e retenção dos profissionais nas organizações. Por meio do treinamento, é possível obter ou melhorar o conhecimento necessário para atingir e eficiência exigida no ambiente de trabalho, contribuindo para o desenvolvimento profissional e pessoal dos profissionais. Ter profissionais capacitados, além de aumentar a produtividade e motivação, faz com que eles estejam aptos a trazer ainda mais soluções e inovações para o dia a dia da empresa. A qualificação de funcionários é a principal maneira de reter talentos, mais do que um salário chamativo e um ambiente agradável. Ter base e recursos para a realização do seu trabalho é imprescindível. Desta maneira, o treinamento e desenvolvimento nas empresas trazem benefícios para todos os envolvidos. O progresso curricular do profissional é capaz de trazer resultados surpreendentes. Vale destacar que esta cultura de intensa valorização do funcionário é peça-chave no sucesso de uma empresa. Este trabalho também destaca a importância de que os programas de treinamento e desenvolvimento sejam seguidos por avaliações de resultados no desempenho dos envolvidos, para que isso possa repercutir na permanência dos talentos. As ferramentas de treinamento são uma forma de garantir uma atualização eficaz de colaboradores, independente da área de atuação da organização.

Palavras-chave: Treinamento e desenvolvimento; Retenção de talentos; Competências; Motivação; Satisfação no trabalho.

\section{Training and development as a tool for retaining talent in organizations}

\begin{abstract}
This paper addresses the importance of the training and development subsystem as a source of training, enhancement and retention of professionals in organizations. Through training, it is possible to obtain or improve the knowledge necessary to achieve and the required efficiency in the workplace, contributing to the professional and personal development of professionals. Having qualified professionals, in addition to increasing productivity and motivation, makes them able to bring even more solutions and innovations to the day to day of the company. Employee qualification is the primary way to retain talent, rather than a flashy salary and a pleasant environment. Having the foundation and resources to perform your work is essential. In this way, training and development in companies bring benefits to all involved. The curricular progress of the professional can bring surprising results. It is worth noting that this culture of intense employee appreciation is a key to a company's success. This work also highlights the importance of training and development programs being followed by performance evaluations on the performance of those involved, so that this can affect the permanence of talents. Training tools are a way to ensure an effective updating of employees, regardless of the organization's area of expertise.
\end{abstract}

Keywords: Training and development; Retaining talent; Skills; Motivation; Job satisfaction.

Topic: Recursos Humanos

Reviewed anonymously in the process of blind peer.
Received: 03/01/2019

Approved: 02/03/2019
Fabiana Capella Azeredo

Centro Universitário Augusto Motta, Brasil http://lattes.cnpq.br/5439438750706607

fabicapella@terra.com.br
Referencing this:

AZEREDO, F. C.. Treinamento e desenvolvimento como instrumento de retenção de talentos nas organizações. Revista Brasileira de Administração Científica, v.10, n.1, p.14-30, 2019. DOI: http://doi.org/10.6008/CBPC2179-684X.2019.001.0002 


\section{INTRODUÇÃO}

Atualmente, muitas organizações precisam criar seu diferencial competitivo a partir dos seus talentos internos por meio de investimentos em capacitação. Além disso, como muitas vezes é impossível a contratação de profissionais com as capacidades requeridas pela organização, as empresas se veem obrigadas a investir em treinamentos para desenvolver as competências necessárias aos seus profissionais, sejam elas por expertise de seus negócios ou para se manterem competitivas no mercado de trabalho. Embora sejam reconhecidamente positivos para as organizações, muitos programas de treinamento não promovem os benefícios esperados, tanto por falta de levantamentos das necessidades, quanto por não haver continuidade em sua aplicação.

Muitas pessoas, embora com elevado conhecimento técnico, não apresentam um nível comportamental adequado à organização. Diante disso a área de Recursos Humanos se vê num dilema: dar prioridade ao requisito técnico ou comportamental no momento do processo seletivo? O que é mais importante para a organização? Por meio das entrevistas de desligamentos já é possível detectar que muitos foram provocados por comportamento inadequado dentro do ambiente organizacional. Isso significa que, atualmente, os gestores estão com dificuldades de liderar suas equipes quando se trata de comportamento organizacional.

Quando tratamos de comportamento organizacional, estamos abordando um conjunto de ações, atitudes e expectativas dos funcionários dentro do ambiente de trabalho. Esse conjunto de ações possui influência direta nos processos organizacionais, sejam esses processos estratégicos, gestão ou operacionais. O bom atendimento é fator primordial em qualquer organização, afinal, ele é o principal canal de comunicação entre a organização e o cliente. No entanto, o número de reclamações sobre o atendimento de várias companhias não para de crescer, ou seja, ao invés de as pessoas observarem melhorias nesse processo, é cada vez mais frequente elas serem mal atendidas e se depararem com profissionais despreparados para determinado tipo de trabalho. A falta de treinamento e reciclagem de suas equipes é o principal motivo que leva as organizações a falharem no quesito atendimento.

Hoje o cliente tem o poder de barganha na compra de produtos ou serviços (havendo uma grande concorrência de mercado) e um dos grandes diferenciais é um atendimento de alta qualidade para atender à expectativa do consumidor. Se existir insatisfação nesse relacionamento, a reação será a busca de outra empresa que ofereça os mesmos serviços ou produtos.

\section{REVISÃO TEÓRICA}

Treinamento é um processo de aprendizado que auxilia o profissional a atingir a eficiência exigida no seu trabalho, ou seja, a capacitação do indivíduo na busca de melhoria ao seu desempenho por meio dos treinamentos aplicados. Para tanto, é preciso saber quais são as necessidades de treinamento, preparar as situações que possibilitem o aprendizado e verificar os resultados (ROBBINS, 2007). 
De acordo com Boog (2003), o mundo atual das organizações é dirigido por um novo conjunto de expectativas: de um lado, certas tendências são o resultado direto da globalização econômica e cultural; do outro, a aprendizagem organizacional e o desenvolvimento dos recursos humanos diante dos desafios que se tornam imprescindíveis, não apenas para o sucesso das empresas, mas para o desenvolvimento social e econômico da sociedade como um todo.

Em outras palavras, conforme Chiavenato (2014), os avanços tecnológicos, as esperanças dos consumidores e cidadãos e as realidades globais têm transformado a maneira pela qual as organizações se relacionam interna e externamente. As abordagens de questões relacionadas à cultura organizacional e ao trabalho vêm passando por mudanças radicais. Os modelos de gestão, muitos deles ultrapassados em decorrência de sua rigidez, estão sofrendo grandes reformas. Os gestores procuram desenvolver competências e aptidões para lidar com situações adversas e os trabalhadores com necessidades cada vez mais complexas (CHIAVENATO, 2014).

O treinamento é um dos muitos recursos utilizados no processo de desenvolvimento com o objetivo de melhorar o desempenho funcional, aprimorar as relações interpessoais e aumentar a produtividade (CECCON, 2013). Conforme comentado por Robbins (2007), para que se entenda a importância do treinamento, faz-se necessário citar o comportamento humano nas organizações (ROBBINS, 2007).

\section{Cultura Organizacional}

Dentro dos estudos da Psicologia Corporativa, a Cultura Organizacional é um tema de grande importância, por ser considerada como fator determinante para o desempenho individual, a satisfação do funcionário e a produtividade da empresa (FAISSAL, 2014). Cultura Organizacional é um sistema de valores que diferenciam uma organização das demais. Esse sistema é um conjunto de características-chave que a organização valoriza (COHEN et al., 2003).

Conforme mencionado por Robbins (2011), quando citou sete características básicas que capturam a essência da cultura de uma organização, tem-se: Inovação e assunção de riscos: significa o grau em que os funcionários são estimulados a inovar e assumir riscos; Atenção aos detalhes: precisão, análise e atenção; Orientação para resultados: focam mais os resultados do que as técnicas e os processos empregados para o seu alcance.

Além desses, tem-se: Orientação para pessoas: o grau em que as decisões dos dirigentes levam em consideração o efeito dos resultados sobre as pessoas dentro da organização; Orientação para a equipe: o grau em que as atividades de trabalho são mais organizadas em termos de equipes do que de indivíduos; Agressividade: o grau em que as pessoas são competitivas e agressivas, em vez de dóceis e acomodadas; e Estabilidade: o grau em que as atividades organizacionais enfatizam a manutenção do status quo em contraste com o crescimento. Existe uma hierarquização nas características que se tornam a base dos sentimentos de compreensão compartilhada que os indivíduos têm a respeito da organização, de como as coisas são feitas e a forma como eles precisam se comportar (ROBBINS, 2011). 
Para que a pessoa possa gerar os resultados esperados pela organização em que trabalha, é preciso que se sinta parte da cultura dessa organização. Dessa forma, ao atrair e selecionar pessoas, o recrutador deve estar atento à identificação de candidatos que possuem valores e crenças compatíveis com os da organização (FAISSAL, 2014).

A cultura organizacional representa as normas informais e não escritas que orientam o comportamento dos indivíduos de uma organização no dia a dia e que direcionam suas ações para o alcance dos objetivos organizacionais. É o conjunto de hábitos e crenças estabelecidos através de normas, valores, atitudes e expectativas compartilhadas por todos dentro da organização (CHIAVENATO, 2014).

\section{Valores Pessoais e Organizacionais}

De acordo com Boog (2003), os valores representam o que os seres humanos valorizam nos relacionamentos com o outro e com o mundo. E um dos principais segredos referentes aos valores é o momento do recrutamento e seleção de profissionais, também chamado de processo seletivo. A partir da avaliação de uma entrevista pessoal, o recrutador consegue buscar no candidato valores pessoais que condizem com os valores organizacionais (ROBBINS, 2007). Conforme Cohen (2013),

Os valores formam o alicerce do caráter da pessoa. Embora alguns dos valores possam mudar no correr da vida, eles tendem a permanecer profundamente enraizados na personalidade. Uma pessoa desenvolve desde cedo um sentido de certo e errado, bem e mal. Muitas das nossas ideias mudam durante a adolescência, mas depois de adultos tendemos a manter e defender algum núcleo básico que está dentro de nós, que nos diz o que é realmente importante na vida e básico para a nossa individualidade.

Nesse sentido, os valores pessoais são aprendidos e desenvolvidos durante o convívio familiar, escolar e nas interações sociais ao longo da existência do indivíduo, enquanto os valores organizacionais são geralmente introduzidos pelo dono ou criador da empresa ou por indivíduos que exercem forte influência no ambiente organizacional (DEMO et al., 2017). A partir do momento que estes valores pessoais se convergem com os valores organizacionais, é um indicador que o recrutador sinaliza como um ponto positivo a ser considerado na escolha do candidato (ROBBINS, 2007). De acordo com Robbins (2007),

Os valores são importantes no estudo do comportamento organizacional porque estabelecem a base para a compreensão das atitudes e motivação, além de influenciarem nossas percepções. As pessoas entram para as organizações com noções preconcebidas das coisas que devem ou que não devem ser feitas.

Logo, o conhecimento do sistema de valores de uma pessoa pode ajudar no entendimento de suas atitudes. Como os valores de cada pessoa são diferentes, a empresa pode utilizá-los como requisito na avaliação e aprovação do candidato (ROBBINS, 2007). Além das aptidões e qualificações requisitadas por qualquer função técnica, o profissional precisa dominar uma lista de valores humanos que se enquadram com os valores organizacionais (DEMO et al., 2017).

Boog (2013) comentou sobre os diferentes tipos de valores humanos e valores organizacionais, a saber: Valores Humanos: Compreensão, empatia, percepção; Interesse, confiança, motivação; Comunicação, clareza, respeito. Valores Organizacionais: Ser produtivo e orientado por resultados; ter visão e estratégias claras para a sua equipe; ser um bom comunicador e saber ouvir a equipe. A compreensão de que os valores 
individuais variam de uma pessoa para outra, mas costumam refletir nos valores da sociedade em que o indivíduo foi criado, é uma valiosa ajuda para a explicação e a previsão de comportamentos (MARRAS, 2005).

É cada vez mais comum grandes empresas adotarem a chamada 'seleção por valores', em que os valores pessoais, ou seja, os propósitos de vida, pesam mais na escolha de um candidato do que sua área de formação, faculdade de primeira linha a até mesmo experiência profissional. O motivo é simples: ao contratar pessoas com valores alinhados aos seus, as empresas acreditam que a relação será mais sólida e duradoura (BARBOSA, 2016).

\section{Características das Competências necessárias para ingressar no mercado de trabalho}

Os valores têm uma influência direta nas atitudes do profissional, elemento composto pelo ideograma conhecido como CHA (Conhecimentos, Habilidade e Atitudes). E serão as atitudes que farão parte do comportamento do profissional no ambiente corporativo (CECCON, 2013). O CHA é um ideograma que define o sentido de competência a partir de um referencial mensurável. O conhecimento é o saber, é o que as pessoas aprendem nas escolas, nas universidades, nos livros, no trabalho e, especificamente, em suas vidas. É geralmente, denominada simplesmente pelo termo, em inglês, Know-How. A habilidade é o saber fazer, é tudo o que de fato é aprendido e utilizado no decorrer da vida. São, basicamente, os arquivos pessoais do dia a dia de cada um. A atitude, por sua vez, é o que leva as pessoas a decidirem se irão ou não exercitar as habilidades de determinados conhecimentos, ou melhor, é o querer fazer (CECCON, 2013).

De acordo com Robbins (2011), atitudes são afirmações avaliadoras, favoráveis ou desfavoráveis. Ou seja, é o reflexo de como o indivíduo se sente em relação a alguma situação, agindo com procedimentos que levam a um determinado comportamento. As atitudes são patenteadas através das reações repetidas de uma pessoa. Este termo tem particular aplicação no estudo do caráter, como indicação inata ou adquirida, relativamente estável, para sentir e atuar de uma forma determinada (COHEN et al., 2003).

A atitude pode culminar em uma determinada postura corporal. Uma atitude ameaçadora é uma postura corporal que expressa agressividade, e pode ser um mecanismo de defesa ou forma de intimidação. Esse tipo de atitude é comum nos seres humanos e em várias outras espécies do reino animal (GONÇALVES, 2016).

\section{Motivação no Ambiente Organizacional}

Na década de 50, no Pós-Fordismo, três teorias foram formuladas para entender como funcionava a motivação dos trabalhadores, conhecidas como Teoria da Hierarquia das Necessidades (Abraham Maslow), Teoria X e Teoria Y (Douglas McGregor) e a Teoria dos Dois Fatores (Frederick Herzberg). De acordo com Robbins (2011), na Teoria da Hierarquia das Necessidades, de Abraham Maslow, existe uma hierarquia de cinco categorias de necessidades dentro de cada ser humano (figura 1). 


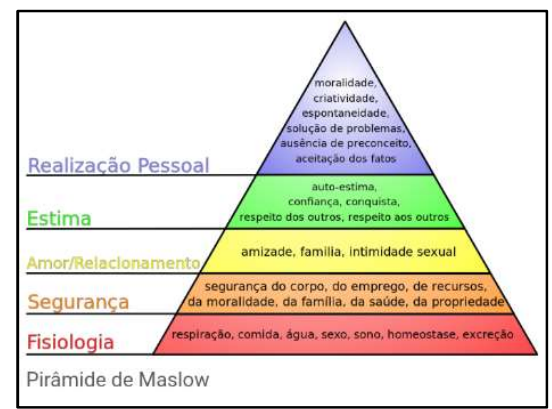

Figura 1: Pirâmide de Maslow. Fonte: Robbins (2011).

A necessidade fisiológica inclui fome, sede, abrigo, sexo e outras necessidades do corpo; Segurança inclui segurança e proteção contra danos físicos e emocionais; Social inclui afeição, aceitação, amizade e sensação de pertencer a um grupo; Estima inclui fatores internos de estima, como respeito próprio, realização e autonomia e fatores externos, como status, reconhecimento e atenção; Autorrealização é a intenção de se tornar tudo aquilo que se é capaz de ser, como crescimento, alcance do seu próprio potencial e autodesenvolvimento.

Na medida em que cada uma destas necessidades é atendida, a próxima se torna dominante. 0 indivíduo move-se para o topo da hierarquia. Do ponto de vista da motivação, esta teoria sugere que, embora jamais uma necessidade possa ser satisfeita completamente, uma necessidade substancialmente satisfeita extingue a motivação. Assim, para motivar alguém é preciso saber em que nível da hierarquia a pessoa se encontra no momento e focar a satisfação naquele nível ou no patamar superior (COHEN et al., 2003).

As necessidades fisiológicas e de segurança são descritas como necessidades de nível mais baixo e aquelas relacionadas à autorrealização são chamadas de necessidades de nível mais alto. A diferenciação entre estes dois níveis parte da premissa de que as necessidades de nível mais alto são satisfeitas internamente (dentro do indivíduo) enquanto as de nível mais baixo são satisfeitas quase sempre externamente, remuneração, acordos sindicais e permanência no emprego (SNELL, 2006).

A Teoria da Hierarquia das Necessidades recebeu amplo reconhecimento, especialmente por parte dos executivos formados na prática. Isto pode ser atribuído à lógica intuitiva da teoria e à facilidade que ela oferece para a compreensão. A segunda teoria da década de 50, a Teoria $X$ e Teoria $Y$, do autor Douglas McGregor propõe duas visões distintas do ser humano: uma basicamente negativa, chamada de Teoria X; e a outra basicamente positiva, chamada de Teoria Y. Observando como os executivos tratavam seus funcionários, McGregor concluiu que a visão que os executivos têm da natureza dos seres humanos se baseia em certos agrupamentos de premissas e que eles tendem a moldar seu próprio comportamento em relação aos funcionários (VERGARA, 2014).

De acordo com Robbins (2011), as quatro premissas dos executivos sob a Teoria X são: Os funcionários não gostam de trabalhar por sua própria natureza e tentarão evitar o trabalho sempre que possível; Como eles não gostam de trabalhar, precisam ser coagidos, controlados ou ameaçados com punições para que atinjam as metas; Os funcionários evitam responsabilidades e buscam orientação formal sempre que possível; e A maioria dos trabalhadores coloca a segurança acima de todos os fatores associados ao trabalho e mostra pouca ambição. 
Em contraste com essas visões negativas, McGregor lista as quatro premissas positivas, chamada Teoria Y: Os funcionários podem achar o trabalho algo tão natural quanto descansar ou se divertir; As pessoas demonstrarão autoorientação e autocontrole se estiverem comprometidas com os objetivos; A pessoa mediana é capaz de aprender a aceitar, ou até a buscar a responsabilidade; e A capacidade de tomar decisões inovadoras pode ser encontrada em qualquer pessoa e não é privilégio exclusivo dos que estão em posições hierarquicamente superiores (ROBBINS 2007).

McGregor acreditava que as premissas da Teoria $\mathrm{Y}$ eram mais válidas que as da Teoria X. Para maximizar a motivação dos funcionários propôs ideias como a do processo decisório participativo, a das tarefas desafiadoras e de muita responsabilidade e a de um bom relacionamento em grupo (VERGARA 2014). Identificada como a terceira teoria da década de 50, a Teoria dos Dois Fatores, criada pelo psicólogo Frederick Herzberg, crê que a relação de uma pessoa com o seu trabalho é básica, e que essa atitude pode determinar o sucesso ou o fracasso. 'O que as pessoas desejam do trabalho?' foi a pergunta investigada por Herzberg. Ele pediu às pessoas que descrevessem situações em que elas se sentiam excepcionalmente bem ou mal a respeito do seu trabalho (CHIAVENATO 2014).

A partir das respostas categorizadas, Herzberg concluiu as respostas referentes aos momentos em que as pessoas se sentiam bem com o trabalho eram significativamente diferentes dos referentes aos momentos em que elas se sentiram mal. Os fatores que levam à satisfação no trabalho são diferentes e separados daqueles que levam à insatisfação (figura 2). Portanto, os executivos que procuram eliminar os fatores que geram insatisfação podem conseguir paz, mas não necessariamente a motivação dos funcionários (SNELL, 2006).

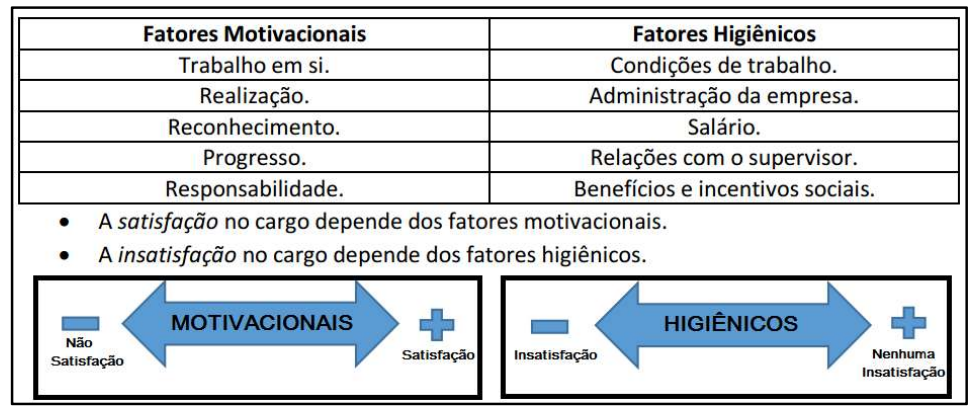

Figura 2: Princípios da teoria motivacional denominada Teoria dos dois Fatores. Fonte: Robbins (2011).

Assim, as condições em torno do trabalho, como a qualidade da supervisão, a remuneração, as políticas da empresa, as condições físicas de trabalho, o relacionamento com os colegas de trabalho e a segurança no emprego foram caracterizadas por Herzberg como fatores higiênicos. Quando os fatores são adequados, as pessoas não estarão insatisfeitas, mas também não estarão satisfeitas. Se quisermos motivar as pessoas para o trabalho, Herzberg sugere a ênfase nos fatores associados com o trabalho em si ou com os resultados diretos dele, como chances de promoção, oportunidades de crescimento pessoal, reconhecimento, responsabilidade e realização. Estas são as características que as pessoas consideram intrinsecamente recompensadoras (ROBBINS, 2014). 
A motivação é um fator considerável no trabalho do indivíduo, e pode ser aumentada quando os funcionários percebem que as recompensas são distribuídas seguindo o critério de desempenho. Vincula-se as teorias sobre motivação com práticas como o envolvimento dos funcionários ou até mesmo a transformação com base nas habilidades (BARBOSA, 2016).

O envolvimento dos funcionários tornou-se um termo genérico que cobre uma grande variedade de técnicas. Esta expressão engloba ideias populares como, por exemplo, a participação dos funcionários ou gestão participativa, democracia no ambiente de trabalho, autonomia e participação acionária dos funcionários. Embora cada uma dessas características tenha suas próprias ideias, todas compartilham de uma essência comum: o envolvimento dos funcionários (SOUZA 2017).

O maior objetivo é estimular toda a capacidade e comprometimento dos funcionários para o sucesso da organização. Por meio do envolvimento dos funcionários naquelas decisões que lhe dizem respeito e do aumento de sua autonomia e controle sobre o seu próprio trabalho, eles se tornarão mais motivados, mais comprometidos com a organização, mais produtivos e mais satisfeitos com o emprego (COHEN, 2003).

O envolvimento dos funcionários foi delineado com base nas teorias sobre a motivação. Por exemplo, a Teoria Y é coerente com a gestão participativa, enquanto a Teoria $\mathrm{X}$ está mais próxima do estilo tradicional autocrático de gerir pessoas. Em termos da Teoria dos Dois Fatores, os programas de envolvimento podem oferecer aos funcionários uma motivação intrínseca, aumentando as oportunidades de crescimento, responsabilidade e envolvimento com o trabalho em si. Da mesma forma, a oportunidade de tomar decisões e implementá-las pode ajudar na satisfação das necessidades dos trabalhadores em termos de responsabilidade, realização, reconhecimento, crescimento e melhoria da autoestima (COHEN, 2003).

\section{A mensuração da Satisfação no Trabalho do funcionário}

A satisfação no trabalho reflete o grau com que o contexto laboral no qual o indivíduo está inserido converge com suas necessidades. Nesse contexto, pode-se citar a influência de fatores externos, relacionados ao próprio trabalho, como: a remuneração, o tipo de atividade realizada, o comportamento da supervisão, as possibilidades de promoção, a interação com a equipe, e as condições físicas e de regras de trabalho praticadas na organização, a estabilidade no trabalho, o desenvolvimento pessoal e a quantidade de trabalho. Soma-se, a esses fatores, as características individuais ou fatores internos, compostos pela experiência, a idade, o gênero e o grau de educação do empregado (CAPPI, 2015).

Na busca por fatores contributivos à construção de satisfação no trabalho, Marques (2015) descreveu oito características que podem ser encontradas em um trabalho percebido como gratificante. Tais qualidades são: A possibilidade de realizar variadas tarefas; Trabalhar em um ambiente considerado seguro nos aspectos físico e psicossocial; Poder proporcionar a renda satisfatória para manter a família e a si; Encontrar propósito percebido como significativo para fazer um produto ou prestar um serviço; Encontrar felicidade e satisfação naquilo que faz; Sentir-se comprometido afetivamente com a causa resultante do trabalho; Perceber que o desempenho no trabalho é satisfatório e que os objetivos estão sendo alcançados; Perceber e sentir companheirismo, lealdade e confiança nas relações estabelecidas com colegas e gestores. 
Para mensurar essa satisfação do funcionário no ambiente organizacional, as empresas aplicam um questionário de avaliação denominado de Pesquisa de Clima. A pesquisa de clima organizacional (figura 3) é uma maneira utilizada para coletar diversos tipos de dados, trazendo sempre muitas informações relevantes sobre qual está sendo a percepção dos funcionários em relação a muitos fatores que podem até mesmo afetar o seu desenvolvimento e satisfação dentro de uma empresa (MARQUES, 2015). Existem muitos objetivos que levam a qualquer tipo de empresa a aderir à pesquisa, entre eles, é o fato de avaliar qual está sendo o grau de satisfação dos funcionários em relação a organização, assim, ao detectar qual é a falha da empresa, é possível solucionar o problema com muita facilidade (CAPPI, 2015).

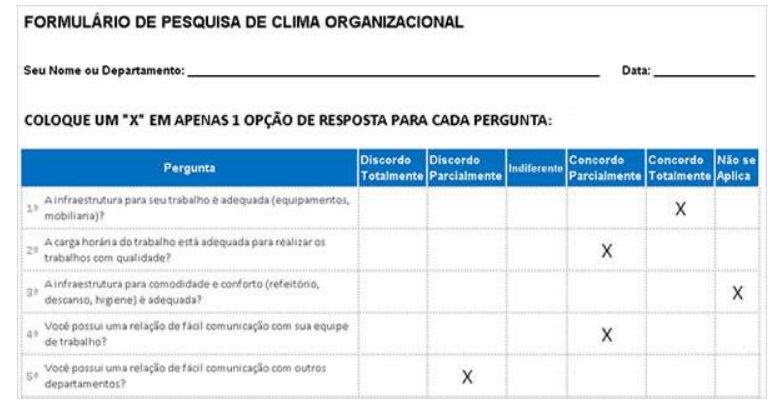

Figura 3: Modelo de Pesquisa de Clima.

\section{Conceito de Recrutamento e Seleção de Profissionais}

De acordo com Chiavenato (2010), o termo recrutamento tem sua origem na área militar: o recrutamento militar é a convocação obrigatória de todo cidadão que atinge determinada idade. Na vida organizacional, o recrutamento é também uma convocação, que também pode ser chamado de convite, porém, sem o comparecimento obrigatório do indivíduo. Ou seja, recrutamento é um sistema de informação das empresas que constituem o mercado de trabalho e é destinado aos candidatos que povoam o mercado de recursos humanos para divulgar as ofertas de emprego.

Sendo assim, o recrutamento pode ser considerado como um processo de localização, identificação e atração de candidatos para a organização (DUTRA, 2016). Atualmente, com o grande desenvolvimento tecnológico e um mundo corporativo com amplo fluxo de informações e competitividade, tem-se a necessidade de pessoas qualificadas, que agreguem valores para compor o ambiente organizacional. Enfrentar desafios a um nível de primazia interna e externa, torna-se possível mediante a um processo de recrutamento e seleção bem aplicados. Segundo Souza (2017), atualmente as organizações que pretendem manter-se competitivas no mercado, precisam investir nos potenciais humanos.

Quando se fala em recrutamento, refere-se à mão de obra para atender as necessidades da empresa, buscando candidatos com perfil adequado para determinada vaga. O objetivo de todo profissional da área de recursos humanos é selecionar o candidato ideal para a vaga solicitada, e o objetivo de toda organização é o sucesso no mercado (GONÇALVES, 2016).

Portanto, uma forma de atingir seus objetivos, faz-se pelas mudanças organizacionais do seu quadro de pessoal. Pois, nos dias dia hoje, as empresas estão sempre em busca de qualidade nos serviços, melhores resultados, almejando maiores lucros e oportunidades. A seleção e o recrutamento contribuem como forma 
de desenvolvimento do planejamento estratégico, buscando a melhoria contínua do capital intelectual e agrega novos valores aos ativos intangíveis da organização (SILVA, 2018).

Atualmente, as empresas são cobradas em inúmeros aspectos, sejam cobranças internas: melhores resultados, maior qualidade na produção; como cobranças externas: cuidados para evitar acidentes de trabalhos, cotas para serem atendidas. Deste modo, para atender estas demandas, o processo de recrutamento e seleção de pessoal deve ter claro seus objetivos e atentar as necessidades de cada etapa exigida (DUTRA, 2016). Há tempos, ao se falar em recursos humanos, associava-se a ideia de folha de pagamento de funcionários de uma empresa; hoje, o recrutamento e seleção de profissionais capacitados é parte integrante das funções deste setor (ROSA, 2004).

Seguir de modo adequado cada etapa do processo de recrutamento e seleção é o que faz a diferença ao final, possibilitando escolher, de acordo com as necessidades do cargo, o candidato mais apto para preencher a vaga. Chiavenato (2010) diz que a escolha de bons profissionais é um aspecto primordial no sucesso organizacional. A seleção de pessoas constitui um investimento em tempo e dinheiro que proporciona excelentes resultados a curto e longo prazo.

Algumas empresas ainda não têm claro o que demanda cada etapa desse processo, recrutamento e seleção, que caminham juntos atraindo e filtrando os candidatos que apresentam requisitos exigidos pelo cargo pretendido, sendo necessário e importante esclarecer a elas, mostrando as vantagens que podem ser atingidas quando são seguidas as fases demandadas (TONET, 2014).

O processo de atração e escolha entre as pessoas e as empresas não é tão simples, mas reduz a incerteza através da qual as pessoas e as organizações buscam conhecer-se reciprocamente e aliviar as diferenças entre si (CHIAVENATO, 2010). São as pessoas que garantem o sucesso de uma empresa, já que são elas que transformam horas trabalhadas em valor, entregando produtos e serviços, solucionando problemas, aceitando desafios, oferecendo experiência e conhecimento nos mais diversos campos (SOUZA 2017).

\section{Treinamento e Desenvolvimento}

Para Marras (2005), treinamento é “um processo de assimilação cultural a curto prazo, que objetiva repassar ou reciclar conhecimentos, habilidade e atitudes relacionados diretamente à execução de tarefas ou à sua otimização no trabalho". A questão do desenvolvimento das pessoas na organização é fundamental para a manutenção ou ampliação do seu diferencial competitivo. As organizações estão cada vez mais pressionadas, tanto pelo ambiente externo, quanto pelas pessoas com as quais mantêm relações de trabalho, a investir no desenvolvimento humano. As organizações estão percebendo a necessidade de estimular e apoiar a contínuo desenvolvimento das pessoas como forma de manter suas vantagens competitivas. Ao mesmo tempo, as pessoas buscam seu contínuo desenvolvimento para obter segurança quanto à inserção no mercado de trabalho (DUTRA, 2016).

Entre os objetivos mais importantes do treinamento, Marras (2005) destaca os seguintes: Formação profissional: alcance de um grau ideal de capacidade laboral para determinada profissão; Especialização: 
oferece um campo de conhecimento ou prática específica dentro de uma área de trabalho; e Reciclagem: revisão de conceitos, conhecimentos ou práticas, atualizando-os de acordo com as necessidades.

Boog (2013) relatou que o investimento em desenvolvimento das pessoas que trabalham na organização terá impacto maior a médio e longo prazo. O primeiro fator que pode ser observado é o aumento da produtividade, que será reforçada principalmente por três fatores: Equipe mais qualificada: esse fator segue uma fórmula simples e básica, que quanto maior for a qualidade da equipe, melhor será o serviço prestado por ela. Consequentemente, isso impacta diretamente nos resultados, pois permite que o trabalho realizado pelos seus colaboradores tenha sempre um alto nível de excelência; Aumento da motivação dos funcionários: ao observar que a empresa investe no aperfeiçoamento de suas competências e sentir que ela se preocupa com seus funcionários, os colaboradores passam a se sentirem mais motivados e dispostos a darem o melhor de si para conseguir alcançar os objetivos da organização.

Por fim, Retenção de talentos: uma empresa que possui em sua cultura organizacional a priorização do investimento em aprimoramento das qualidades e competências de seus colaboradores contribui para a criação de um elo mais forte com eles. Isso coopera não só para um bom relacionamento e melhores resultados, mas também para reter talentos. Impedir a saída de quem importa é essencial para uma organização. Marras (2005) afirmou que as etapas de elaboração de um programa de treinamento corporativo são: Levantamento das Necessidades de Treinamento (diagnóstico), Programação de Treinamento, Execução do Treinamento e Avaliação dos Resultados do Treinamento (figura 4).

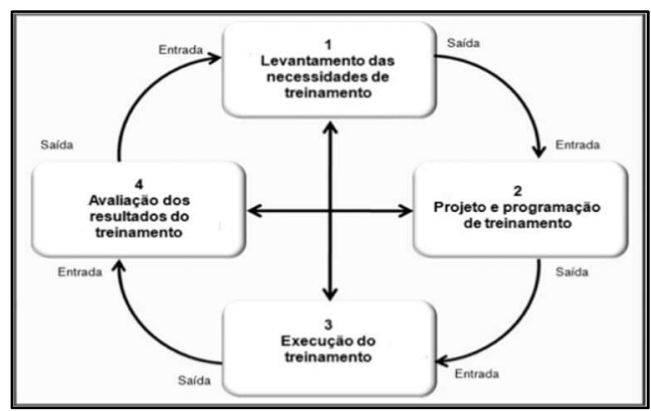

Figura 4: Esquema das etapas do processo de Treinamento e Desenvolvimento. Fonte: Marras (2005).

\section{Levantamento de Necessidades de Treinamento}

Na primeira etapa, Marras (2005) aborda que o diagnóstico representa o levantamento e a análise que dão subsídio ao plano de treinamento, o que é chamado de levantamento de necessidades de treinamento (LNT). É nesse ponto que a área de recursos humanos faz sua primeira análise comparativa entre o perfil atual do profissional e as exigências organizacionais.

O Levantamento de Necessidades de Treinamento (LNT) engloba pesquisa e a respectiva análise pela qual se detecta o conjunto de carências cognitivas e inexperiências relativas ao trabalho. Esse conjunto de carências provoca uma ineficiência indesejada pela organização e se origina no próprio recrutamento e seleção dos profissionais. Sempre haverá diferenças de perfil nos trabalhadores recém-admitidos, que levam a organização a implementar ações de treinamento para ajustar tais diferenças (PELIZZARO, 2014). 


\section{Projeto e Programação do Treinamento}

Após o levantamento das necessidades de treinamento, devem ser analisados os dados obtidos, dando início ao planejamento dos programas, o qual deve estar direcionado aos objetivos da organização. 0 planejamento do treinamento seria uma decorrência do diagnóstico das necessidades (PELIZZARO, 2014), tendo como propósito evitar a improvisação que leva à incerteza; é uma projeção de intenções com base em fatos passados e presentes que apontam as diretrizes e procedimentos para atingir as metas propostas (CARVALHO, 2001).

Essa etapa do processo de treinamento consiste em analisar e coordenar as ações consideradas prioritárias e necessárias para serem implementadas em módulos de aprendizagem, conforme previamente planejado (MARRAS, 2005). Nesta fase, são definidos os locais, datas, coordenadores, instrutores e eventos. A programação poderá ser trimestral, semestral ou anual, dependendo das variáveis como: situação política e econômica do país, posição da organização no mercado, novidades tecnológicas, entre outros (CARVALHO, 2001).

\section{Execução do Treinamento}

Após definido o planejamento, é necessária a organização do treinamento: organizar e delegar responsabilidades, expor os planos para os executivos, divulgar o programa de treinamento, produzir os materiais e verificar os equipamentos necessários (BOOG, 2013). Marras (2005) explica que a execução do treinamento é a aplicação daquilo que foi planejado e programado para suprir as necessidades de aprendizagem, detectadas na organização. Ressaltando as duas grandes preocupações com a execução: a qualidade da aplicação dos módulos e a eficiência do resultado. Realizados os treinamentos, é necessário que ele seja avaliado (BOOG, 2013).

\section{Avaliação dos Resultados do Treinamento}

Essa é a última etapa do treinamento. Tem por finalidade aferir os resultados obtidos comparativamente àquilo que foi planejado e esperado pela organização. O preenchimento do questionário deve ser feito sempre ao término do treinamento (MARRAS, 2005). Avaliar a reação dos participantes de um treinamento é como medir a satisfação dos clientes de uma organização. Na avaliação de reação, são analisados: o instrutor, o conteúdo programático, o material didático, os recursos utilizados, a carga horária e as instalações. Essa avaliação oferece informações aos responsáveis pelos treinamentos, além de avaliar o desempenho dos instrutores, contribuindo para a melhoria do treinamento (MORAES, 2011).

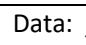


Caso a sua resposta tenha sido não, justifique.

\section{A escolha dos temas e a sequência foram adequadas?}

$\square \operatorname{Sim} \square$ Não

Caso a sua resposta tenha sido não, justifique.

Avalie os tópicos a seguir dando-Ihes uma nota de 1 a 5 (inteiros):

Considere: 5 = (Ótimo); 4 = (Bom); 3 = (Regular); e 1 e 2 = (Ruim).

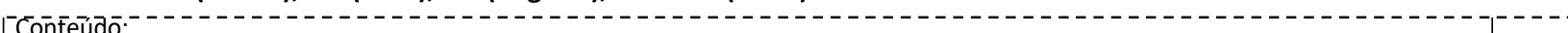

Utilização do Tempo:

Clareza na Explanação:

Interação com o Instrutor:

Clareza no esclarecimento de dúvidas:

Relevância do assunto no seu dia a dia:

0 Evento correspondeu às suas expectativas?

$\square \operatorname{Sim} \square$ Não

Caso a sua resposta tenha sido não, justifique.

Sugestões e Comentários Gerais:

Figura 5: Questionário Avaliação de Reação do Treinamento Aplicado.

A análise dos resultados não pode ser feita unicamente com base nos benefícios financeiros (CARVALHO, 2001). Nesse sentido, para Tachizawa et al. (2006), a avaliação deve verificar como foi realizado o treinamento e qual o resultado obtido, sejam em termos organizacionais, humanos, tarefas e operações. A avaliação seria uma comparação dos objetivos pretendidos com os resultados efetivamente alcançados.

\section{Tendências de Treinamento no Brasil}

As rápidas mudanças tecnológicas, sociais, políticas e econômicas, além da queda das barreiras geográficas, têm afetado incisivamente as dinâmicas das organizações contemporâneas. A instabilidade gerada repercute diretamente na busca por modelos eficientes de desenvolvimento de novas competências profissionais, de forma a garantir continuamente recursos e clientes para organizações inseridas em um cenário altamente competitivo. Nesse contexto, a área de treinamento, desenvolvimento e educação de pessoas cada vez mais assume relevância nas organizações, pois conforme destaca Loiola et al. (2006), a capacidade de aprender gera impactos positivos na sustentabilidade das condições de competitividade e de sobrevivência das organizações (SILVA, 2002).

Com a participação de mais de mil organizações que atuam no Brasil, Boog (2013) coordenou pesquisa sobre as tendências de treinamento e desenvolvimento chamada 'Retrato do Treinamento no Brasil', apontando dois grandes temas que nortearam as ações de treinamento e desenvolvimento no Brasil para as próximas duas décadas, a saber: Ampliação da utilização de mecanismos e sistemas tecnológicos com novos significados no intercâmbio de informações e compartilhamento do conhecimento; Novos investimentos em diversos setores da economia que aceleram as ações de desenvolvimento dos profissionais. 
De acordo com a pesquisa, as principais tendências referentes ao primeiro tema são a multiplicação e integração de diferentes mídias e recursos para tornar o treinamento mais atrativo e versátil. Já no segundo tema, enfatiza como tendência a ampliação da oferta de treinamento como parte da estratégia de engajamento e retenção de talentos. A identificação dessas tendências é baseada na expansão da economia brasileira logo, as organizações devem se preparar para o cenário que está por vir, especialmente em grandes organizações brasileiras e em multinacionais que operam no Brasil ou possuem forte relação com operações na América Latina (BOOG, 2013).

Baseado em Boog (2013) e até os dias de hoje não houve relatos científicos sobre o atual cenário do impacto dos treinamentos organizacionais possivelmente devido à crise econômica que se instalou no Brasil. Porém, pode-se encontrar artigos não científicos ou científicos na mídia impressa com atualizações constantes correlatas.

De acordo com a pesquisa realizada pela empresa Integração Escola de Negócios, denominada O Panorama do Treinamento no Brasil: fatos, indicadores, tendências e análises realizada em 2017, mostrou que as empresas brasileiras destinaram $0,63 \%$ do faturamento anual bruto para o investimento anual em Treinamento e Desenvolvimento, um número que cresceu 37\% em relação ao ano anterior, mais uma vez demonstrando uma tendência de crescimento, mesmo em um ano em que a prioridade das organizações foi a contenção de despesas. Talvez agora seja a preparação para a retomada, um momento muito estratégico.

A pesquisa relatou que o cenário econômico é advindo de uma aguda crise político-econômica, na qual as empresas têm reduzido seus custos e otimizado seus processos, buscando atravessar este momento desafiador, culminando em um ano de 2017 ainda difícil, mas já com consistentes sinais de retomada. Mesmo em momentos de cortes, as empresas continuam investindo no desenvolvimento de seus profissionais. Equipes reduzidas, porém, com muita ênfase em seu progresso e na qualidade de seu trabalho.

\section{Os desafios de treinar e desenvolver diferentes gerações}

Quando se realiza um treinamento, o instrutor depara-se muitas vezes com várias gerações no mesmo espaço. Cada uma possui suas características, por isso é importante conhecer as gerações que estão atuando nas organizações. Atualmente, algumas gerações convivem no mercado de trabalho, e todas buscam seus próprios interesses. As gerações $\mathrm{X}$ e $\mathrm{Y}$ representam a grande maioria dos profissionais atualmente em uma organização. Elas apresentam grande diferença de personalidade e características que devem ser trabalhadas, evitando os conflitos (MORAES, 2011).

Gerir pessoas com perspectivas tão distintas sobre valores, hierarquia, equilíbrio trabalho, vida, dinheiro, carreira, entre outras diferenças, exige um esforço no sentido de compreender melhor os vetores que mais influenciam cada uma dessas gerações. Assim, é possível definir estratégias que proporcionem um ambiente de trabalho mais harmônico e produtivo (GRUBB, 2018).

Nascida entre 1945 e 1960, a geração Baby Boomers, foi marcada pelo final da Segunda Guerra Mundial. Seu principal ideal era reconstruir o mundo. Para eles o trabalho era a principal razão da vida. Alguns profissionais dessa geração ainda estão na ativa e com vasta experiência. As principais características dessa 
geração são: ascensão profissional com uma profunda ética profissional, valorização do status, vaidade, briga pelos direitos civis e agir em consenso com os demais (MORAES, 2011).

Os nascidos entre 1960 e 1980, chamada de Geração X, tiveram que aprender a lidar com a tecnologia após a década de 1980 e dominar novas línguas para ter acesso a novos mercados. Atualmente, a geração X domina a hierarquia na maioria das organizações, possuindo boa experiência profissional. Um aspecto muito forte desta geração é a comunicação. As principais características são: autoconfiança, ética profissional, busca da individualidade sem perder a convivência em grupo, maturidade e escolha de produtos de qualidade (GARCIA, 2008).

A geração Y, nascidos entre 1980 e 1995, foi marcada pela revolução tecnológica. O ideal dessa geração é a globalização, multicultura e diversidade. Define o trabalho como "satisfação do desejo de consumismo" (GARCIA, 2008). O trabalho é sinônimo de colaboração, aprendizado e diversão. Buscam grandes desafios e são abordados constantemente por organizações que oferecem planos de carreira atrativos, o que causa uma redução no tempo de permanência na organização atual. As principais características são: imediatistas, em busca de informação fácil e imediata, digitação em vez de escrita, conhecimento não aprofundado, imposição de valores e multitarefas (MORAES, 2008).

Uma das vantagens de investir esforços no desenvolvimento desses jovens é que eles chegam ao mercado de trabalho sem vícios. Portanto, fica muito mais fácil treiná-los. São multitarefas, otimistas e abertos às mudanças. Ao mesmo tempo, também são mais ansiosos, angustiados e desapegados com as coisas. Por isso, é preciso tomar alguns cuidados na hora de prepará-los para ocupar posições de liderança (GARCIA, 2008). Os jovens são, definitivamente, o assunto do momento. Eles buscam constantemente desafios e muitas vezes ignoram as regras hierárquicas tradicionais. Porém, desempenham bem o trabalho enquanto escutam música e navegam em redes sociais (BOOG, 2013).

Nascidos entre 1996 e 2009, a geração Z está entrando no mercado de trabalho. Atualmente, muitos ainda representados pelos menores aprendizes. As relações com essa geração são totalmente virtuais. Apresentam sérios problemas de interação social e comunicação. São profissionais com uma compreensão tecnológica apurada, abertos a novas tecnologias e com raciocínio rápido. Essas características acabam gerando certa impaciência, e a rotina frequente atrelada a processos burocráticos pode ser desanimadora para esses jovens. Como principais características, agilidade, resistência a lidar com frustrações, não são fiéis a empregos e com a tecnologia aguçada (CODEÇO, 2014).

Para Moraes (2011), a próxima geração será definida, do alfabeto grego, como Alfa. Será a geração dos nascidos a partir de 2010 e será caracterizada pela instrução e educação. Todas as gerações têm o que ensinar e a aprender umas com as outras, por exemplo, um profissional mais velho deve compreender que o mais novo possui os atributos da inovação e da energia para lidar com as novidades. Já os mais novos precisam atingir o equilíbrio e a capacidade de pensar estrategicamente com os mais velhos, o que torna suas decisões estatisticamente mais acertadas. A empresa do futuro é aquela capaz de conciliar diferentes gerações em um mesmo ambiente de trabalho, extraindo o que cada uma tem de melhor e equilibrando os potenciais individuais em função do bem-estar coletivo (TONET et al., 2014). 


\section{CONCLUSÕES}

O treinamento e desenvolvimento nas empresas desempenham um papel essencial na qualificação de funcionários, interferindo diretamente com os resultados da sua empresa. Uma boa gestão, aliada à constante atualização de equipe, capacita e desenvolve habilidades diversas de colaboradores, trazendo benefícios de curto e longo prazo. A cada capacitação, o profissional sai cada vez mais qualificado e motivado, e isso se torna um grande diferencial para o negócio. Em tempos de altíssima competitividade, é preciso que gestores fiquem de olho nas principais tendências de mercado, a fim de manter seu time alinhado, fortalecido e estimulado.

Ter profissionais capacitados, além de aumentar a produtividade e motivação, faz com que eles estejam aptos a trazer ainda mais soluções e inovações no dia a dia da empresa. A qualificação de funcionários é a principal maneira de reter talentos, mais do que um salário chamativo e um ambiente agradável. Ter base e recursos para a realização do seu trabalho é imprescindível.

Desta maneira, o treinamento e desenvolvimento nas empresas trazem benefícios para todos os envolvidos. O progresso curricular do profissional é capaz de trazer resultados surpreendentes. Vale destacar que esta cultura de intensa valorização do funcionário é peça-chave no sucesso de uma empresa. Através da atualização e adequação às principais tendências de mercado, é possível manter uma equipe entusiasmada e produtiva.

Por isso, é essencial que a gestão da empresa esteja sempre em sintonia com o setor de Recursos Humanos, responsável pela administração dos talentos da empresa. Mais do que isso, é preciso que todos estejam a par das novas tendências da área. Assim, é possível aplicar um treinamento e desenvolvimento corporativo assertivo e altamente produtivo.

Crescer na carreira é um objetivo que sempre esteve associado à ideia de subir degraus e ocupar posições cada vez mais altas em estruturas organizacionais com hierarquias claras e bem definidas. As ferramentas de treinamento são uma forma de garantir uma atualização eficaz de colaboradores, independente da área de atuação da organização. O departamento de Recursos Humanos deve atuar como uma ponte entre os setores, fazendo com que todos possam mostrar valores e resultados de forma prática. Engajamento e competitividade são as palavras de ordem para atingir objetivos e, dependendo do caso, superar expectativas.

\section{REFERÊNCIAS}

BANOV, M. R.. Recrutamento, seleção e competências. 4 ed. São Paulo: Atlas, 2015

BARBOSA C. L.; LOPES I. C.. Empresas versus Processos Seletivos: A importância do Recrutamento e Seleção para o Desenvolvimento Organizacional. Revista de Administração e Comércio Exterior, v.2, n.1, 2016.

BOHLANDER, G. W.; SNELL, S.; SHERMAN, A.. Administração de recursos humanos. São Paulo: Pioneira Thomson Learning, 2003.
BOOG, G. G.; BOOG M.. Treinamento e Desenvolvimento: Gestão e Estratégias. 6 ed. Campinas: Pearson, 2013.

BORGES, L. O.; MOURÃO, L.. O trabalho e as organizações: atuações a partir da psicologia. Porto Alegre: Artmed, 2013.

CAPPI, M. N.; ARAUJO B. F. B.. Satisfação no trabalho, comprometimento organizacional e intenção de sair: um estudo entre as gerações X e Y. Revista Eletrônica de Administração, v.21, n.3, 2015. 
CARVALHO, A. V.. Treinamento: Princípios, métodos e técnicas. São Paulo: Pioneira, 2001.

CECCON, J. J.. Os Conhecimentos, Habilidades e Atitudes necessários aos novos gestores em suas tomadas de decisão. Rio de Janeiro: 2013.

CHIAVEnATO, I.. Gestão de Pessoas: O novo papel dos recursos humanos nas organizações. 4 ed. São Paulo: Manole, 2014.

CHIAVENATO, I.. Iniciação à Administração de Recursos Humanos. 4 ed. São Paulo: Manole, 2010.

CHIAVENATO, I.. Treinamento e Desenvolvimento de Recursos Humanos: como incrementar talentos na empresa. 7 ed. São Paulo: Manole, 2014.

CODEÇO, P. V.. Gerações $X$ e $Y$ e seus perfis motivacionais. Curitiba: Annris, 2014

COHEN, A. R.; FINK, S. L.. Comportamento Organizacional: Conceitos e estudos de casos. 7 ed. Amsterdã: Elsevier, 2003.

DEMO, G.; FERNANDES, T.; FOGAÇA, N.. A Influência dos valores organizacionais na percepção de políticas e práticas de gestão de pessoas. Revista Eletrônica de Administração, v.23, n.1, 2017

DUTRA J. S.. Gestão de Pessoas: modelos, processos, tendências e perspectivas. 2 ed. São Paulo: Atlas, 2016

FAISSAL, R.; PASSOS, A. E. V. M.; MENDONÇA, M. C. F.; ALMEIDA, W. M. C.. Atração e seleção de pessoas. 2 ed. Rio de Janeiro: FGV, 2014.

GARCIA, P.. Quem é a geração Y. HSM Management, n.70, 2008.

GOMES, E. B. P.; FIACO, J. L. M.; RABELO, A. A.. Análise de procedimentos de seleção de pessoal. Gestão, inovação e negócios, v.3, n.1, 2017.

GONCALVES, A. P. V.; PROBST, M.. Gestão de Pessoas. Maiêutica, v.4, n.1, p.57-64, 2006.

GRUBB, V. M.. Conflito de Gerações: desafios e estratégias para gerenciar quatro gerações no ambiente de trabalho. São Paulo: Autêntica Business, 2018.
KANAANE, R.; ORTIGOSO, S. A. F.. Manual de treinamento e desenvolvimento do potencial humano. 2 ed. São Paulo: Atlas, 2010.

MARQUES, J. R.. Coaching e Capital Humano:

Potencializando pessoas e organizações. Goiânia: IBC, 2015.

MARRAS, J. P.. Administração de recursos humanos. 11 ed São Paulo. Futura, 2005.

MORAES, M. V. G.. Treinamento e Desenvolvimento: educação corporativa para as áreas de saúde, segurança do trabalho e recursos humanos. São José dos Campos: Érica, 2011.

PELIZZARO, R.; ALVES, J. N.; RIBAS, F. T. T.; BALSAN L. A. G.. A Percepção dos Colaboradores em relação ao Processo de Treinamento e Desenvolvimento: um estudo de caso. Uniabeu Belford Roxo, v.7, n.15, 2014.

ROBBINS, S. P.. Comportamento Organizacional: Teoria e prática no contexto brasileiro. 14 ed. Campinas: Pearson, 2011.

SILVA, G. G.; MENESES, P. P. M.. Necessidades De Treinamento Organizacional e Motivação para Trabalhar. Revista Eletrônica de Administração, n.1, p.27, 2012.

SILVA, J. M.; BRAVIN, A. A.. Resenha: Análise de Cargo, recrutamento e seleção: manual prático para aumentar a eficácia na contratação de profissionais. Psicologia: Teoria e Pesquisa, v.34, 2018.

SNELL, B.. Administração: Novo Cenário Competitivo. 6 ed. São Paulo: Atlas, 2006.

SOUZA, G. B. P.; LOPES, P. S.; SILVA, L. C. F.; RODRIGUES, M. A Gestão de Talentos Atualmente Adotada pelas Organizações. Revista Científica Univiçosa, v.9, n.1, 2017.

TACHIZAWA, T.; FERREIRA, V. C. P.; FORTUNA, A. A. M. Gestão com pessoas: uma abordagem aplicada às estratégias de negócios. Rio de Janeiro: FGV, 2006.

TONET, H.; REIS, A. M. V.; BECKER JUNIOR, L. C.; COSTA, M. E. B.. Desenvolvimento de Equipes. 2 ed. Rio de Janeiro: FGV, 2014

VERGARA, S. C.. Gestão de Pessoas. 15 ed. São Paulo: Atlas, 2014.

A CBPC - Companhia Brasileira de Produção Científica (CNPJ: 11.221.422/0001-03) detém os direitos materiais desta publicação. Os direitos referem-se à publicação do trabalho em qualquer parte do mundo, incluindo os direitos às renovações, expansões e disseminações da contribuição, bem como outros direitos subsidiários. Todos os trabalhos publicados eletronicamente poderão posteriormente ser publicados em coletâneas impressas sob coordenação da Sustenere Publishing, da Companhia Brasileira de Produção Científica e seus parceiros autorizados. Os (as) autores (as) preservam os direitos autorais, mas não têm permissão para a publicação da contribuição em outro meio, impresso ou digital, em português ou em tradução. 